\title{
Publisher Correction: 78,000-year-old record of Middle and Later Stone Age innovation in an East African tropical forest
}

\author{
Ceri Shipton (1) 1,2,3, Patrick Roberts ${ }^{4}$, Will Archer ${ }^{5,6}$, Simon J. Armitage ${ }^{7,8}$, Caesar Bita9 , James Blinkhorn 4,10, \\ Colin Courtney-Mustaphi1 ${ }^{11}$, Alison Crowther ${ }^{2,12}$, Richard Curtis ${ }^{13}$, Francesco d' Errico ${ }^{8,14}$, Katerina Douka ${ }^{4,15}$, \\ Patrick Faulkner ${ }^{16}$, Huw S. Groucutt ${ }^{4,17}$, Richard Helm ${ }^{18}$, Andy I.R. Herries (1) ${ }^{13}$, Severinus Jembe ${ }^{19}$, \\ Nikos Kourampas 20,21, Julia Lee-Thorp ${ }^{17}$, Rob Marchant ${ }^{10}$, Julio Mercader ${ }^{22}$, Africa Pitarch Marti ${ }^{14,23}$, \\ Mary E. Prendergast ${ }^{24}$, Ben Rowson ${ }^{25}$, Amini Tengeza ${ }^{19}$, Ruth Tibesasa ${ }^{26}$, Tom S. White 27,28 , \\ Michael D. Petraglia (i) ${ }^{4,29} \&$ Nicole Boivin 4
}

Correction to: Nature Communications https://doi.org/10.1038/s41467-018-04057-3, published online 09 May 2018.

The originally published version of this article contained an error in Fig. 3, whereby an additional unrelated graph was overlaid on top of the magnetic susceptibility plot. Furthermore, the Article title contained an error in the capitalisation of 'Stone Age'. Both of these errors have now been corrected in both the PDF and HTML versions of the Article.

\footnotetext{
${ }^{1}$ McDonald Institute for Archaeological Research, University of Cambridge, Downing Street Cambridge, CB2 3DZ Cambridge, UK. ${ }^{2}$ British Institute in Eastern Africa, Laikipia Road, Kileleshwa, Nairobi, Kenya. ${ }^{3}$ Centre of Excellence for Australian Biodiversity and Heritage, Australian National University, Canberra, ACT 2601, Australia. ${ }^{4}$ Department of Archaeology, Max Planck Institute for the Science of Human History, Kahlaische Strasse 10, Jena D-07745, Germany. ${ }^{5}$ Department of Human Evolution, Max Planck Institute for Evolutionary Anthropology, Deutscher PI. 6, Leipzig 04103, Germany. ${ }^{6}$ Department of Archaeology, University of Cape Town, Rondebosch 7701 Western Cape, South Africa. ${ }^{7}$ Department of Geography, Royal Holloway, University of London, Egham, Surrey TW20 OEX, UK. ${ }^{8}$ SSF Centre for Early Sapiens Behavior (SapienCe), University of Bergen, Øysteinsgate 3, Postboks 7805, Bergen 5020, Norway. ${ }^{9}$ Malindi Museum, National Museums of Kenya, Malindi, Kenya. ${ }^{10}$ Department of Archaeology, Classics and Egyptology, University of Liverpool, 12-14 Abercromby Square, Liverpool L69 7WZ, UK. ${ }^{11}$ Department Environment, York Institute for Tropical Ecosystems, University of York, Heslington, York Y010 5NG, UK. ${ }^{12}$ School of Social Sciences, The University of Queensland, St Lucia, QLD 4072, Australia. ${ }^{13}$ Department of Archaeology and History, The Australian Archaeomagnetism Laboratory, Palaeoscience Labs, La Trobe University, Melbourne Campus, Bundoora, VIC 3086, Australia. ${ }^{14}$ UMR 5199 PACEA, CNRS/Université de Bordeaux, Bâtiment B18, Allée Geoffroy Saint Hilaire, CS, 50023 - 33615 PESSAC CEDEX, France. ${ }^{15}$ Research Laboratory for Archaeology and the History of Art, Dyson Perrins Building, South Parks Road, Oxford OX1 3QY, UK. ${ }^{16}$ Faculty of Arts and Social Sciences, Department of Archaeology, The University of Sydney, Sydney, NSW, Australia. ${ }^{17}$ School of Archaeology, University of Oxford, 36 Beaumont Street, Oxford OX1 2PG, UK. ${ }^{18}$ Canterbury Archaeological Trust, 92A Broad Street, Canterbury, Kent CT1 2LU, UK. ${ }^{19}$ Coastal Forests Conservation Unit, National Museums of Kenya, Kilifi, Kenya. ${ }^{20}$ Centre for Open Learning, University of Edinburgh, Paterson's Land, Edinburgh EH8 8AQ Scotland, UK. ${ }^{21}$ Biological and Environmental Sciences, University of Stirling, Stirling FK9 4LA Scotland, UK. ${ }^{22}$ Department of Anthropology and Archaeology, University of Calgary, 2500 University Drive, Calgary, AB T2N 1N4, Canada. ${ }^{23}$ Grup de Recerca Aplicada al Patrimoni Cultural (GRAPAC), Department of Animal Biology, Plant Biology and Ecology, Faculty of Biosciences, Autonomous University of Barcelona (UAB), Campus Bellaterra, Bellaterra 08193, Spain. ${ }^{24}$ Department of Sociology and Anthropology, Saint Louis University, Avenida del Valle 34, Madrid 28003, Spain. ${ }^{25}$ Invertebrate Biodiversity, National Museum Wales, Cathays Park, Cardiff CF10 3NP, UK. ${ }^{26}$ Department of Anthropology and Archaeology, University of Pretoria, cnr Lynnwood Road and Roper Street, Hatfield, South Africa. 27 University Museum of Zoology, Cambridge Downing Street, Cambridge CB2 3EJ, UK. ${ }^{28}$ Department of Life Sciences, The Natural History Museum, Cromwell Road, London SW7 5BD, UK. ${ }^{29}$ Human Origins Program, Smithsonian Institution, Washington, DC 20560, USA. Correspondence and requests for materials should be addressed to C.S. (email: ceri.shipton@anu.edu.au) or to P.R. (email: roberts@shh.mpg.de) or to N.B. (email: boivin@shh.mpg.de)
} 
Published online: 05 June 2018

(c) Open Access This article is licensed under a Creative Commons Attribution 4.0 International License, which permits use, sharing, adaptation, distribution and Ceproduction in any medium or format, as long as you give appropriate credit to the original author(s) and the source, provide a link to the Creative Commons license, and indicate if changes were made. The images or other third party material in this article are included in the article's Creative Commons license, unless indicated otherwise in a credit line to the material. If material is not included in the article's Creative Commons license and your intended use is not permitted by statutory regulation or exceeds the permitted use, you will need to obtain permission directly from the copyright holder. To view a copy of this license, visit http://creativecommons.org/licenses/by/4.0/.

(C) The Author(s) 2018 